\title{
Simulation Analysis of MOSFET Based Absorber for Reflected RF Signal in 5G Massive MIMO Base Station
}

\author{
Elliot O. Omoru, Viranjay M. Srivastava \\ Department of Electronic Engineering, Howard College, University of KwaZulu-Natal, Durban-4041, South Africa \\ viranjay@ieee.org
}

\begin{abstract}
The reduce the effects of losses, due to the reflection of RF signals from the receiver (connected to circulators) in 5G massive MIMO base station, an N-channel MOSFET have been proposed as a solution. In the proposed model, theoretical relationships between drain current and source current of the Nchannel MOSFET have been used. Simulation experiment has been performed to verify the correctness in operation, consistency, and theoretical relationship between the sources and drain current. The experiment closely monitored the values of drain and source current at different reflection condition under appropriate gate voltage. To monitor these parameters, the peak voltage component of the reflected power at each chosen instance were calculated and its equivalent direct current voltage value was applied to the drain terminal of the MOSFET. This research focuses on examining the consistency of the parameters and theories used for the MOSFET based absorber under different reflection condition from ports of circulators in $5 \mathrm{G}$ base stations.
\end{abstract}

Key words : Base station, MOSFET, Fifth generation (5G), Circulators, Radio Frequency, Transceiver.

\section{INTRODUCTION}

The next generation of technology in the telecom industry is the emergence of $5 \mathrm{G}$ technology which promises instantaneous connectivity to billions of devices, massive machine to machine communication also called the Internet of Things (IoT), etc. [1$3]$. The 5Ginitially operates in conjunction with existing 4G networks before evolving fully to standalone networks in subsequent releases. In addition, to deliver faster connectivity at greater capacity, a very important advantage of $5 \mathrm{G}$ is its fast response time referred as latency. The $3 \mathrm{G}$ networks had atypical response time of 100 milliseconds, $4 \mathrm{G}$ is around 30 milliseconds and $5 \mathrm{G}$ as low as 1 millisecond [2-4]. In addition to these major use cases, the $5 \mathrm{G}$ provides the right environment for ultrareliable low latency communication system, including real-time control of devices, industrial robotics, and vehicle to vehicle safety communication [5-7].

Furthermore, one major loss anticipated in the 5G technology are due to reflection of signals from the receiver $\left(\mathrm{R}_{\mathrm{X}}\right)$ branch connected to the circulators in 5G MIMO base station. This reflection loss is due to mismatched load impedance of the $\mathrm{R}_{\mathrm{X}}$ branch with the source impedance of the transmitter $\left(\mathrm{T}_{\mathrm{X}}\right)$ branch thus affecting the overall performance of the base station. This problem can be solved by designing an impedance matching circuit between the $T_{X}$ and $R_{X}$ branch of the base station. But it gives another challenge of impedance matching circuit design, most especially at high-frequency and microwave regime. Isolating the branches with the help of a circulator and absorbing any reflected signal proves to be a better alternative. The main objective of this research is to use the MOSFET to absorb the reflected signal resulting from impedance mismatching between the $T_{x}$ and $R_{x}$ of the base station [8-10].

To carry out simulation, models for simulation were insufficient, for this reason a sinusoidal voltage source have been used to provide an equivalent source or $\mathrm{T}_{\mathrm{X}}$ branch terminal voltage component of Incident RF power. With the help of a voltage divider, the voltage component of reflected RF power from the $\mathrm{R}_{\mathrm{X}}$ branch connected to the circulator was generated and applied to the input terminal of the rectifier used in the proposed model. With these values, calculations were carried out to determine the capacitance and inductance values used for the filter design to obtain a pure $\mathrm{DC}$, as rectified $\mathrm{AC}$ signal is pulsating in nature. More information about the circuit description is detailed in ref. [11]. The resultant DC voltage was applied to the drain terminal of the MOSFET and the condition for MOSFET absorption was tested for four values of reflection from port-4 to verify the consistency of various established theories.

This paper is organized as follows. Section 2 discusses the prerectification process of reflected radio frequency signal from the $\mathrm{R}_{\mathrm{X}}$ branch of the base station. Section 3 discusses the rectification process of reflected radio frequency signal. Section 4 discusses the filtration and absorption process with analysis of simulation and results. Finally, Section 5 concludes the work and recommends the future aspects.

\section{BASICS OF RF RECTIFICATION PROCESS}

The $\mathrm{T}_{\mathrm{X}}$ branch, $\mathrm{R}_{\mathrm{X}}$ branch, and antenna branch are connected together by a four-port circulator, the function of the circulator is to route radio frequency signal between all branches connected to it [12-15]. It is non-reciprocal (behaviour in one direction is different from their behaviour in another direction). Power is transferred from one port to the adjacent port in a prescribed 
order. It is a device used for transmission in which microwave or radio frequency signal entering any port are passed on to the next port in rotation. A port in this context is the point where an external wave guide or transmission line is connected to the device $[13,14]$.

\subsection{Circulator Basics and Advancements}

A novel three-port active circulator was proposed by Moussa et. al. [16]. This circulator was composed of a phase divider with one transistor and a special form of Wilkinson power splitter operating as a power combiner. An active quasi-circulator at 30 $\mathrm{GHz}$ was designed and fabricated by Chang et. al. [17] at TSMC 0.18- $\mu \mathrm{m}$ mixed-signal CMOS technology. The current reuse technique was integrated with a common source stage to form the quasi-circulator core with reduced power consumption. A three-port active circulator and active quasi-circulator based on the bridged-T network was designed and fabricated by Wang et. al. [18] at standard 0.18- $\mu \mathrm{m}$ CMOS technology. An active quasicirculator MMIC was designed and fabricated by Shin et. al. [19] at standard $0.18-\mu \mathrm{m}$ CMOS technology. It combines the common source, common gate, and common drain configurations to improve the isolation between ports, and improved insertion loss.

The circulator can be used as isolator / duplexer or can perform both operations in a transmission system [20-22]. In a four-port circulator, signal entering by port- 1 exits the circulator via port2 , signal entering by port- 2 exits the circulator via port- 3 , signal entering through port-3 exits the circulator via port-4, lastly, signal entering the circulator via port- 4 exits the circulator via port-1. Fig 1 shows the port connection of a basic circulator. The modulated RF signal from the $\mathrm{T}_{\mathrm{X}}$ branch of the base station flows into the circulator via the port- 1 of the circulator.

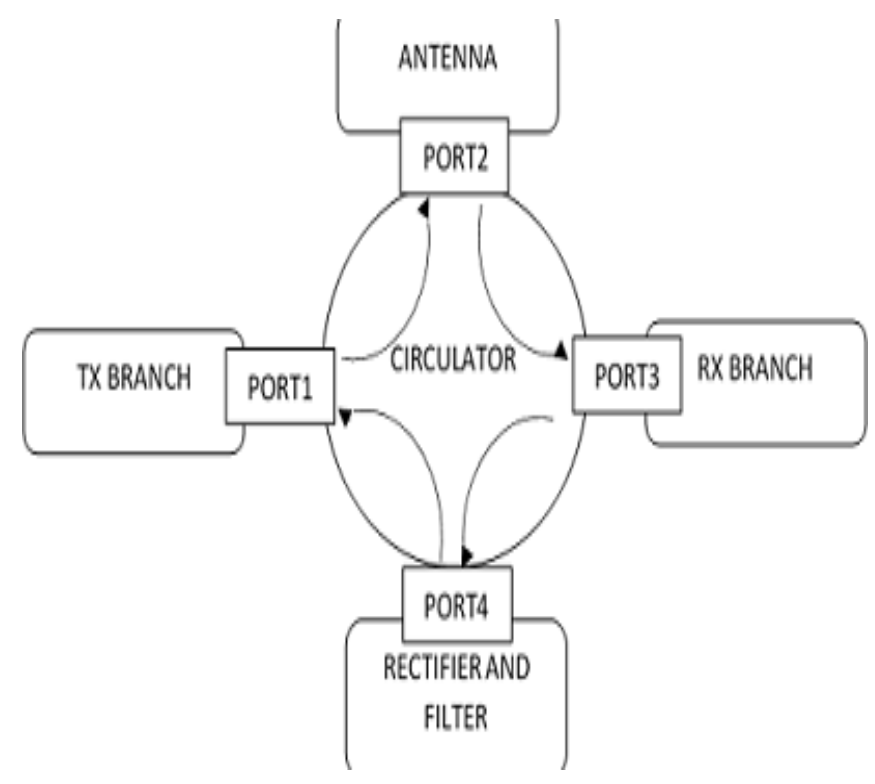

Figure 1: Basic model of RF pre-rectification.
The circulator receives this signal and sends it out through its port- 2 which has a band pass filter connected to it. The band pass filter limits the RF signal to the frequency desired for transmission. Connected band pass filter is a transceiver which performs the function of propagating the RF signal into space. The propagated RF signal is received by the transceiver of a neighbouring base station, the signal enters into the circulator via the port- 2 of the circulator in the neighbouring base station and it's outputted through port- 3 which has the $\mathrm{R}_{\mathrm{X}}$ branch connected to it. Whenever there is a mismatch between the $\mathrm{T}_{\mathrm{X}}$ of the transmitting base station and the $\mathrm{R}_{\mathrm{X}}$ branch of the neighbouring base station, some of the signal will be reflected back. The reflected signal from the port- 3 of the neighbouring base station exits the circulator via its port- 4 which has a rectifier connected to it. As stated in the Section I, models for simulation were insufficient to provide real ports for this reason a sinusoidal voltage source have been used to provide an equivalent source or $\mathrm{T}_{\mathrm{X}}$ branch terminal voltage component of Incident RF power. With the help of a voltage divider, the voltage component of reflected $\mathrm{RF}$ power from the $\mathrm{R}_{\mathrm{X}}$ branch connected to the circulator was generated and applied to the input terminal of the rectifier used in the proposed model.

$$
V_{\text {OUT }}=V_{I N}\left[\frac{R_{2}}{R_{1}+R_{2}}\right]
$$

where $V_{\text {in }}$ is Source or $T_{X}$ branch terminal voltage component of incident $R F$ power and $V_{\text {out }}$ is the component of reflected $R F$ power from $R_{X}$ branch. The values of resistors $\left(R_{1}\right.$ and $\left.R_{2}\right)$ required to produce a voltage drop equivalent to the voltage component of the reflected RF power from the $\mathrm{R}_{\mathrm{X}}$ branch has been generated with the help of an online software.

Considering $19 \mathrm{dBm}$ reflection loss from the $\mathrm{R}_{\mathrm{X}}$ branch of the base station, the values of resistors $\left(R_{1}\right.$ and $\left.R_{2}\right)$ required to produce a voltage drop equivalent to the voltage component of reflected RF power are $108.95 \Omega$ and $1700 \Omega$, respectively. Substituting these values into(1), with $\mathrm{V}_{\text {in }} 44.662 \mathrm{~V}$, the achieved $\mathrm{V}_{\text {out }}$ will be $2.69 \mathrm{~V}$.

Table 1: Values for resistors needed to produce the required output voltage output

\begin{tabular}{|c|c|c|c|c|}
\hline $\begin{array}{c}\text { Reflected RF } \\
\text { power P }(\mathrm{dBm})\end{array}$ & $\mathrm{V}_{\text {in }}$ (Volts) & $\mathrm{V}_{\text {out }}($ Volts $)$ & $\mathrm{R} 1(\Omega)$ & $\mathrm{R} 2(\Omega)$ \\
\hline 19 & 44.67 & 2.69 & 108.95 & 1700 \\
\hline 13 & 44.67 & 1.44 & 56.64 & 1700 \\
\hline 5 & 44.67 & 0.56 & 21.82 & 1700 \\
\hline 3 & 44.67 & 0.45 & 17.19 & 1700 \\
\hline
\end{tabular}

Similar calculations have been carried out for three other cases of reflection from the $\mathrm{R}_{\mathrm{X}}$ branch connected to the circulator and the equivalent resistor values where recorded in Table 1 . However, these chosen cases may not always be the case, they have been used to accurately predict and evaluate the model. 


\subsection{Rectification of Reflected RF Signal}

The ultimate goal of $5 \mathrm{G}$ base station is efficiency of various component used for its construct. For this reason, a full wave rectifier was used in place of a half way rectifier as it produces twice the efficiency of a half wave rectifier. Though, the use of two additional diodes for the rectifier construct is a disadvantage because each of the diodes causes a voltage drop, thus reducing the voltage at the output terminal of the rectifier [23-25]. However, considering the conditions for MOSFET absorption and the working of the MOSFET voltage drop is not a major concern in this research and has a minimal effect in overall research conclusion.

Putting all these into consideration a voltage source representing the reflected radio frequency power from the port- 4 of the circulator, is applied to the input terminal of the rectifier and a combination of $2 k \Omega$ resistor and the four-diode combination carries out the rectification process taking into consideration the on and off states of the diodes and the potentials at each nodes of the rectifier as shown in Fig.2.During the positive half cycle diode $\mathrm{D}_{1}$ and diode $\mathrm{D}_{3}$ are in ON state, for the negative half cycle diode $\mathrm{D}_{2}$ and diode $\mathrm{D}_{4}$ are in ON state and the type of wave present at the output of the rectifier in this case is a pulsating in nature.

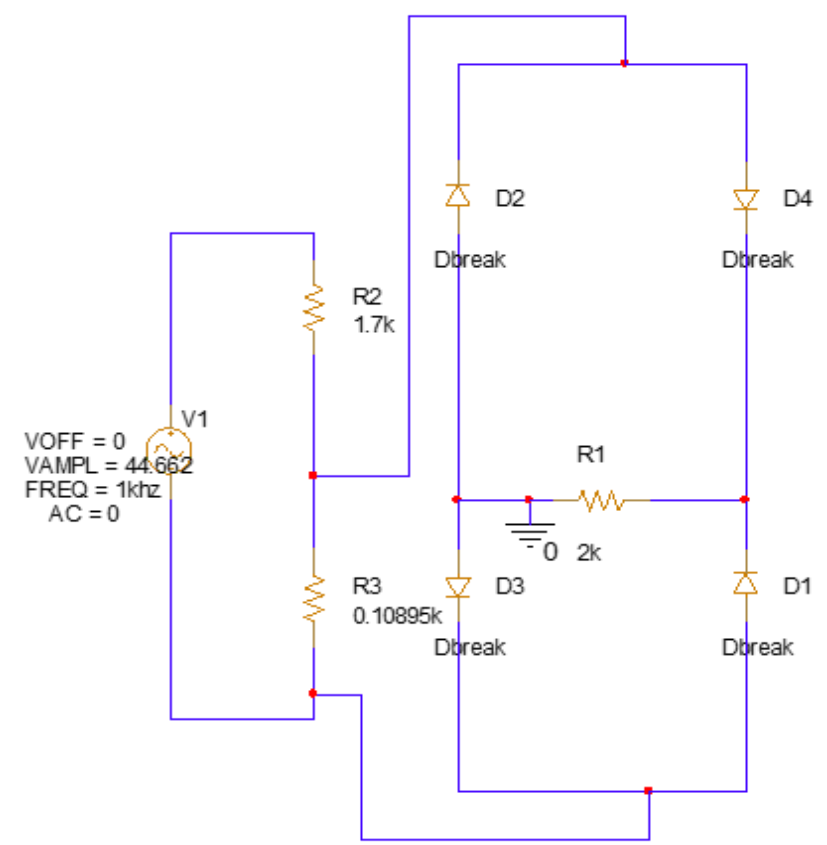

Figure 2: Basics of rectification of reflected RF signal.

In the rectifier configuration (Fig. 2), the diodes keep switching connections to the resistor through the various available nodes so that current flows in only one direction through the resistor. The resistor can be replaced with any other circuit, including more power supply circuitry (such as the LC filter), and still realize the same behaviour from the bridge rectifier as explained in further sections.

\section{FILTERATION OF PULSATING DC SIGNAL WITH THE DESIGNED CIRCUIT (MOSFET BASED ABSORBER)}

For a MOSFET device to function properly, it is important to apply a pure and consistent DC signal to the drain terminal of the MOSFET, as the signal from the output of the rectifier connected to the circulator is pulsating [26-28]. To achieve a pure DC, a capacitor and an inductor have been connected in parallel and in series respectively with a load resistor [29, 30]. This capacitor filters the variation in voltages at the output of the rectifier, while the inductor filters the variation in current. Without the capacitor a pulsating DC signal will exists but with the capacitor and inductor, the variation will be lesser.

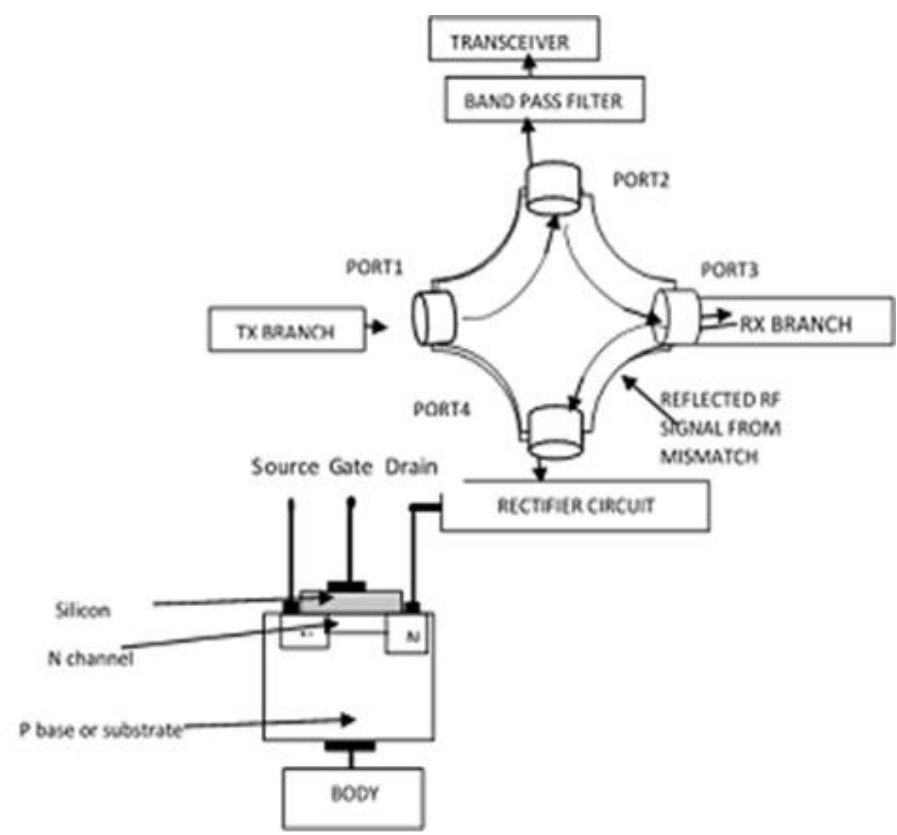

Figure 3: Designed model of MOSFET based absorber (with the reflected signal in 5G mMIMO base station) [11].

When the voltage is rising, the capacitor stores the charge (charging mode), absorbing energy from the circuit. When the voltage across the load resistor is decreasing, the capacitor releases its stored energy into the circuit thus preventing the voltage from dropping so low. When the voltage rises again the capacitor absorbs the energy from the circuit thus preventing the voltage from rising too quickly. By the capacitor absorbing and releasing energy to the circuit it causes the voltage to be more consistent rather than falling quickly and then rising quickly. It smoothens out the pulsating DC signal.

The variation in voltages after filtering is called a ripple voltage. Reduction in the ripple voltage is achieved by increasing the value of the capacitor value or increasing the load resistor which may not always have control over [31-34]. In addition to this, capacitance selection is an important issue in the circuit, even though it is a very effective way of reducing the ripple voltage it also has a problem. 
Elliot O. Omoru et al., International Journal of Emerging Trends in Engineering Research, 8(9), September 2020, 6488 - 6495

The inductor has the same effect as the capacitor, but in this case when current goes up the inductor will oppose the increase in current and it does so by absorbing energy and storing it in his expanding magnetic field. When the current goes down the magnetic field produced by the inductor releases its stored energy back to the circuit, thus supporting the falling currents.

\section{SIMULATION ANALYSIS OF DESIGNED CIRCUIT}

For simulation, a sinusoidal voltage source has been used to provide the equivalent reflected power from the $\mathrm{R}_{\mathrm{X}}$ branch of the base station. The frequency of the voltage source has been set to $1 \mathrm{kHz}$ instead of $5 \mathrm{G}$ standard frequency, because at $5 \mathrm{G}$ frequencies the concept of voltages and current becomes difficult to relate during simulation. In addition to this When frequencies are too high for discrete capacitors and inductors to be practical, a combination of Schottky diode and distributed circuit will be employed for the rectification during the physical implementation of the proposed model at 5G frequency. Furthermore, a lower frequency has been used to reduce the simulation time which is dependent on frequency.

\subsection{Simulation Analysis for Basic Model}

The basic circuit (Fig. 2)has been simulated and the equivalent values of peak voltages and current have been deduced from the input plots. Parameters such as root mean square value of voltage, current, and peak-power have been calculated from the resulting values of peak voltages at the input terminal of the rectifier $[29,30]$.The generated wave form usually has voltage or current plot against time. The horizontal axis shows the passing of time, progressing from left to right. The vertical axis shows the quantity measured which in this case voltage or current. Fig 4 shows the wave forms of voltages and current at the input of the rectifier circuit of Fig. 2. Fig 5 shows the wave forms of pulsed values voltages and current at the output of the rectifier circuit of Fig. 2. From the pulsed values of various voltages and currents deduced from the output plot of the rectifier, parameters such as ripple factor expected DC current have been calculated and recorded. In addition to this the output plot of the rectifier has a combination of $\mathrm{AC}$ and $\mathrm{DC}$ characteristic which is not ideal for proper functioning of MOSFET.

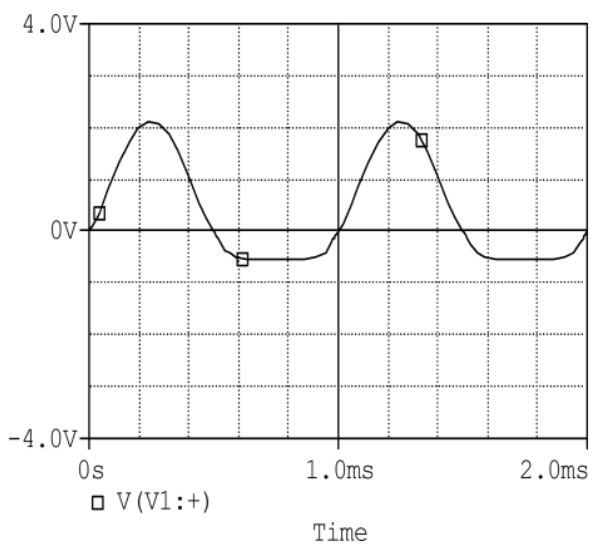

(a)

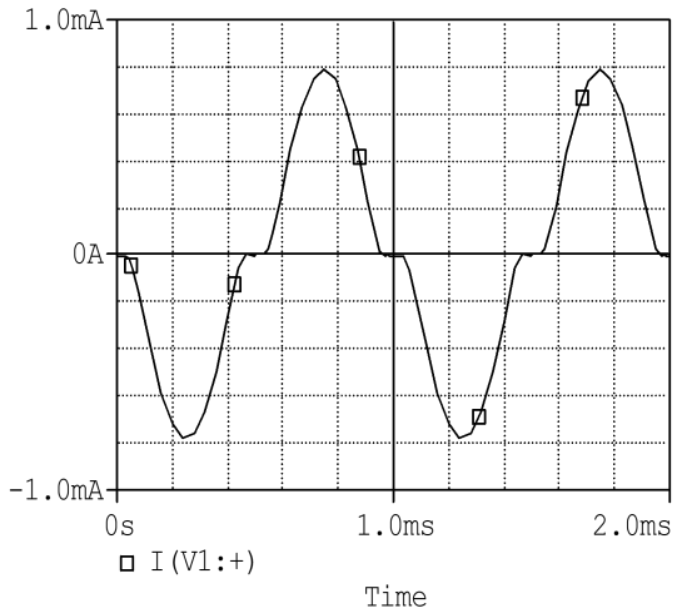

(b)

Figure 4: Plot for rectifier input (a) voltage, and (b) current.

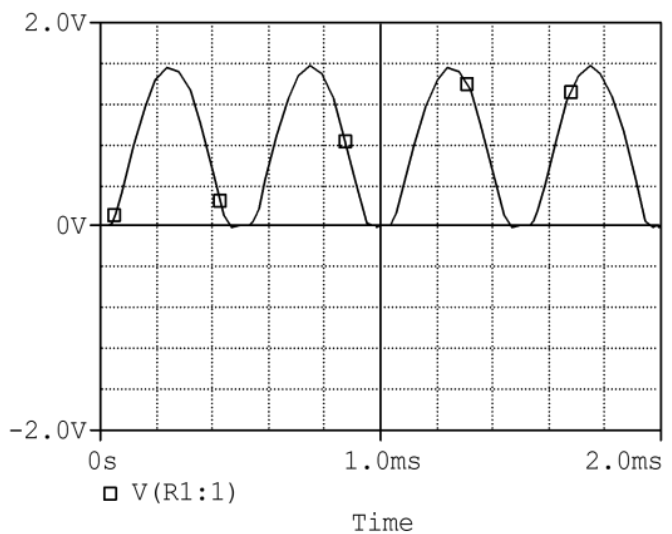

(a)

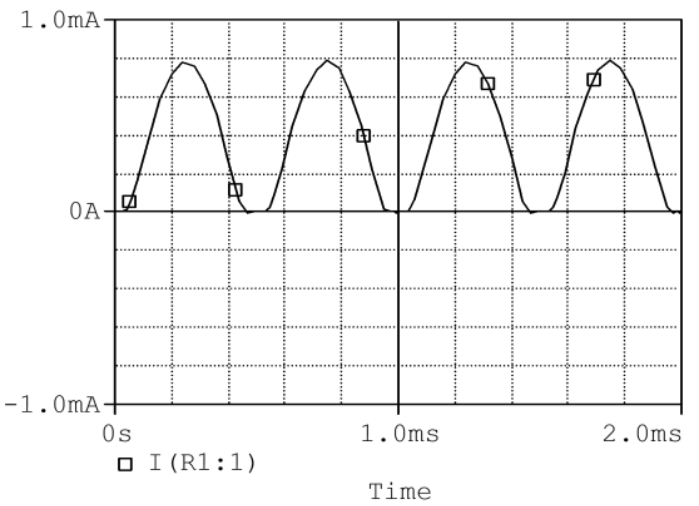

(b)

Figure 5: Plot for rectifier output (a) voltage, and (b) current.

Power supply with very low noise and DC ripple are required for MOSFET. For this reason, the output of the rectifier must be filtered using highly efficient filters. In the simulation an LC filter has been used. To achieve a smooth output, the values of capacitors and inductors have been calculated from the values of voltages and currents deduced from the plots of waveforms as shown in Fig. 5. From the plots, the peak values of voltages and currents are $1.6 \mathrm{~V}$ and $0.8 \mathrm{~mA}$, respectively. From these values, the values of different parameters needed to calculate the rating of capacitor and inductor used for the filter design have been 
determined. However, on the physical implementation of the proposed model the values of capacitor, inductor, and resistor in the rectifier circuit will be tuned to meet the frequency requirement of the $5 \mathrm{G}$ base station. In addition, the proposed model is largely dependent on the frequency at which the rectifier circuit is designed,

Therefore, $V_{r m s}=0.707 \times 1.6=1.13 \mathrm{~V}, V_{D C}=\frac{2 V_{p e a k}}{\pi}=1.02 \mathrm{~V}$, $I_{r m s}=0.707 \times I_{\text {peak }}=0.56 m A$. Expected value of $I_{\mathrm{DC}}$ has been calculated as: $I_{D C}=\frac{2 I_{p e a k}}{\pi}=0.588 \mathrm{~mA}$. To calcuate load resistance $\left(\mathrm{R}_{\mathrm{L}}\right)$ use the formula as: ${ }_{R_{L}}=\frac{V_{m}}{\mathrm{I}_{m}}, \mathrm{~V}_{\mathrm{m}}=\mathrm{V}_{\text {peak }}=1.6 \mathrm{~V}$, and $\mathrm{I}_{\mathrm{m}}=\mathrm{I}_{\text {peak }}=0.8 \mathrm{~mA}$.

Substitute values of peak voltages and current the value calculated for $R_{L}=2 \mathrm{~K} \Omega$. Values of capacitor and inductor for LC filter design is dependent on ripple factor:

$$
\text { RippleFactor }=\frac{\sqrt{I_{r m s}^{2}-I_{D C}^{2}}}{I_{D C}}
$$

Substitute values of $\mathrm{I}_{\mathrm{rms}}$ and $\mathrm{I}_{\mathrm{DC}}$ will give ripple factor0.463. To calculate the impedance of the inductor: $X_{L}=\frac{V_{p e a k}}{I_{r m s}}$. Therefore, at $\mathrm{V}_{\text {peak }}=1.6 \mathrm{~V}$, and $\mathrm{I}_{\mathrm{rms}}=0.566 \mathrm{~mA}$, the value of $X_{L}=2829$ $\Omega$.The inductance can be calculated as $X_{L}=2 \pi f L$, where $f$ is the frequency, then $\mathrm{L}=0.45 \mathrm{H}$. To calculate the impedance of the capactor:

$$
\text { RippleFactor }=\frac{X_{C_{1}} \times X_{C_{2}} \sqrt{2}}{3 X_{L}}
$$

But $X_{C 1}=X_{C 2}=X_{C}$

$$
\text { RippleFactor }=\frac{X_{C}^{2} \sqrt{2}}{3 X_{L}}
$$

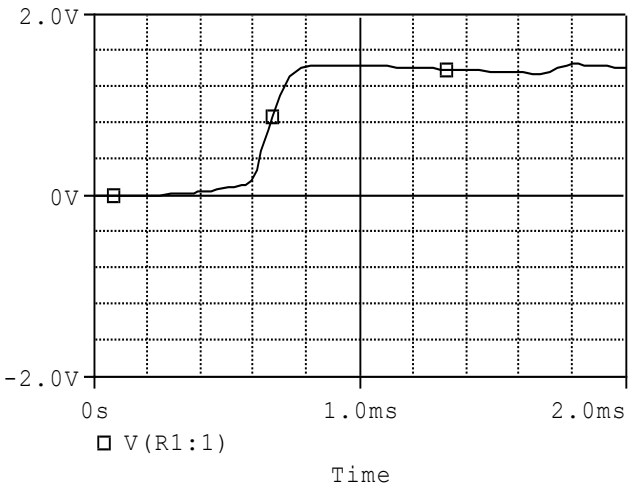

(a)

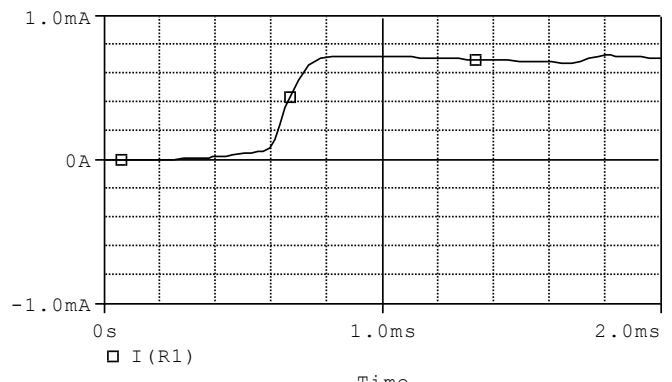

(b)

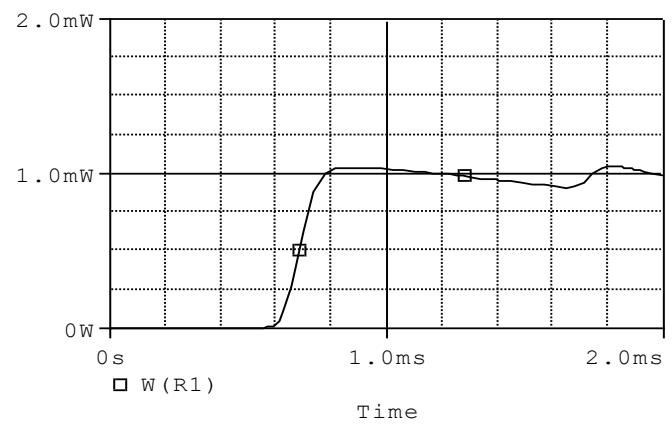

(c)

Figure 6: Plot for rectifier filtered output (a) voltage, (b) current, and (c) power.

Substitute the values of $\mathrm{R}_{\mathrm{L}}, \mathrm{X}_{\mathrm{L}}$, and ripple factoor, the calculated value is $X_{C}=74.6 \Omega$. To achieve maximum filtering the impedance must be higher than the impedance of the capacitor. To calculate the value of the capacitor $C$ :

$$
C=\frac{1}{2 \pi f X_{C}}
$$

Substitute values of $f$ and $X_{C}$, then the achieved $C=2.15 \mu F$.Fig. 6 shows the resulting plots for pure voltage, current, and power respectively. From these output plots the values of voltages and current at the drain and source terminal have been deduced after performing a transient analysis using the p-spice software. However, values may not be exact but error from plots are insignificant.From the plots it can be deduced that $\mathrm{V}_{\mathrm{DC}}=1.4 \mathrm{~V}$, $\mathrm{I}_{\mathrm{DC}}=0.6 \mathrm{~mA}$, and $\mathrm{P}_{\mathrm{DC}}=1.03 \mathrm{~mW}$.

\subsection{Simulation Analysis of Designed Circuit (MOSFET Based Absorber)}

In this simulation analysis, four cases of reflection $(19 \mathrm{dBm}, 13$ $\mathrm{dBm}, 5 \mathrm{dBm}$, and $3 \mathrm{dBm}$ reflection losses) from port-3 of the circulator have been examined to determine the consistency of various parameters used in the model [20, 21, 35-38]. At these conditions, the values of $V_{D S}$ increases at the same rate as the reflected signal because reflected signal varies directly as $V_{D S}$ :

$$
P=\frac{1}{R}\left(\frac{V_{p e a k}}{\sqrt{2}}\right)^{2}
$$


Elliot O. Omoru et al., International Journal of Emerging Trends in Engineering Research, 8(9), September 2020, 6488 - 6495

Using (4) and formulas in previous sections, the input values of voltages and currents of the rectifier have been calculated at different condition of reflection from port- 4 of the circulator and recorded as shown in Table 2.

Table 2: Rectifier input terminal parameters

\begin{tabular}{|c|c|c|c|c|}
\hline $\begin{array}{c}\text { Reflected RF } \\
\text { power }(\mathrm{dBm})\end{array}$ & $\mathrm{V}_{\text {peak }}(\mathrm{V})$ & $\mathrm{V}_{\mathrm{rms}}(\mathrm{V})$ & $\begin{array}{c}\mathrm{I}_{\mathrm{DC}}(\mathrm{mA}) \\
\text { Expected }\end{array}$ & $\begin{array}{c}\text { ripple } \\
\text { factor }\end{array}$ \\
\hline 19 & 1.6 & 2 & 0.8 & 0.463 \\
\hline 13 & 0.45 & 1 & 0.22 & 0.385 \\
\hline 5 & 0.0065 & 0.4 & 0.033 & 0.446 \\
\hline 3 & 0.002 & 0.316 & 0.001 & 0.443 \\
\hline
\end{tabular}

Table 3: Rectifier output terminal parameters

\begin{tabular}{|c|c|c|c|c|c|}
\hline $\begin{array}{c}\text { Reflected } \\
\text { RF power } \\
\mathrm{P}(\mathrm{dBm})\end{array}$ & $\begin{array}{c}\text { Reflected } \\
\mathrm{RF} \\
\text { power(W) }\end{array}$ & $\mathrm{V}_{\text {peak }}(\mathrm{V})$ & $\begin{array}{c}\mathrm{V}_{\text {rms }}(\mathrm{V} \\
)\end{array}$ & $\begin{array}{c}\mathrm{I}_{\text {peak }} \\
(\mathrm{mA})\end{array}$ & $\begin{array}{c}\mathrm{I}_{\mathrm{rms}} \\
(\mathrm{mA})\end{array}$ \\
\hline 19 & 0.080 & 2.7 & 2.0 & 0.80 & 0.56 \\
\hline 13 & 0.020 & 1.44 & 1.0 & 0.22 & 0.15 \\
\hline 5 & 0.0032 & 0.56 & 0.4 & 0.033 & 0.023 \\
\hline 3 & 0.002 & 0.447 & 0.316 & 0.001 & 0.0007 \\
\hline
\end{tabular}

At the output terminal of the rectifier the values of peak voltages and current are pulsating as shown in Fig. 6 and Fig. 7. From the simulation experiment these values were deduced from the output plot, and its equivalent rms value generated and recorded in the Table 3. From the plots the peak values and rms values of current at the input and output terminal of the rectifier were the same.

For a MOSFET to function effectively the values of applied current and voltages must be pure rather than pulsating, to generate a pulsating $\mathrm{DC}$ the output of the rectifier must be filtered as explained in section IV(A) [29, 30]. Using the formulas in section IV the value of capacitance $\mathrm{C}$ and inductance $\mathrm{L}$ were calculated and recorded is shown in Table 4 . With the values of parameters in Table 2 and Table 4 the equivalent circuit of the proposed model has been designed using the ps-pice software as shown in Fig. 7. To run the simulation for the proposed model, the threshold voltage of the MOSFET was set to 0.8 Vand the gate voltage was gradually increased until the MOSFET was fully ON at $9.5 \mathrm{~V}$. After running the simulation, the value of current and voltage at the source and drain terminal of the MOSFET were measured at different reflection condition from port-4 to verify the correctness of the relationship.

Table 4: Filter design parameters

\begin{tabular}{|c|c|c|}
\hline Reflected RF power $(\mathrm{dBm})$ & $\mathrm{L}(\mathrm{H})$ & $\mathrm{C}(\mathrm{uF})$ \\
\hline 19 & 0.450 & 2.15 \\
\hline 13 & 0.478 & 3.22 \\
\hline 5 & 0.450 & 3.12 \\
\hline 3 & 0.455 & 3.3 \\
\hline
\end{tabular}

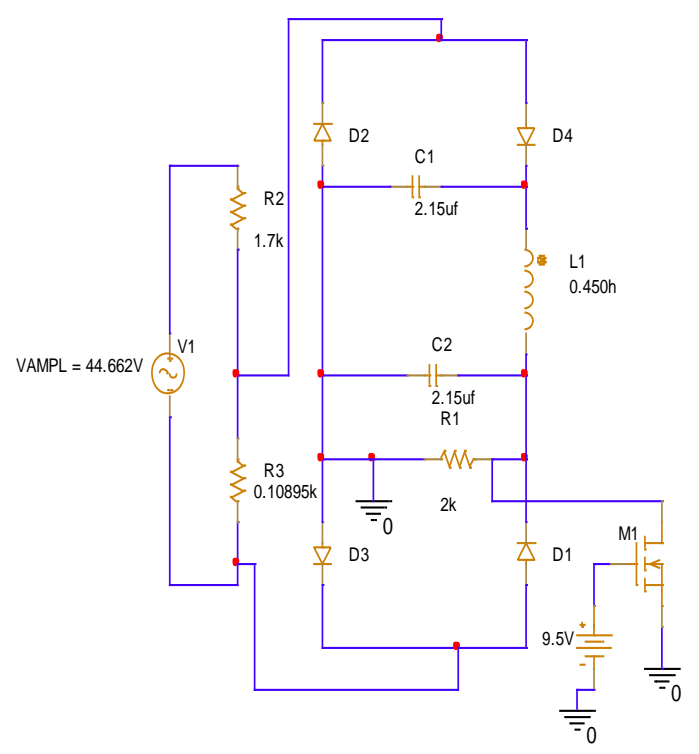

Figure 7: Circuit for MOSFET based absorber of reflected RF signal.

For MOSFET:

$$
\begin{aligned}
& I_{S}=\left[\mu_{n} C_{o x}\left(\frac{W}{L}\right) V_{G S}-V_{t}\right] V_{D S} \leq I_{D} \\
& I_{S}=\left[\mu_{n} C_{o x}\left(\frac{W}{L}\right)\left(V_{o v}-\frac{V_{D S}}{2}\right)\right] V_{D S} \leq I_{D}
\end{aligned}
$$

The purpose of the research is targeted towards using a MOSFET to absorb reflected RF power in $5 \mathrm{G}$ base station the relationship $I_{S} \leq I_{D}$ and $V_{D S}=0$ at the source terminal of the MOSFET must be consistent for all cases of reflection from port4 of the circulator.

Fig. 9 shows the plots of voltages at the drain and source terminal of MOSFET, under $19 \mathrm{dBmreflection}$ from port-4 of the circulator. There is a voltage drop from $1.4 \mathrm{~V}$ to $0 \mathrm{~V}$ because of MOSFET's channel resistance which can be calculated as:

$$
R_{D S}=\frac{1}{\left[\mu_{n} C_{o x}\left(\frac{W}{L}\right) V_{G S}-V_{t}\right]}
$$

Similarly, values of voltages and currents at sources and drain terminal were deduced from plots at different values of reflection and recorded in Table 6 . The MOSFET is said to have performed its function of absorbing reflected radio frequency signal if and only if the relationship $I_{S} \leq I_{D}$ and $V_{D S}=0$ at the source terminal is satisfied, else, the model has failed. Using Table 4, in putting the values of voltages and current into the relationship $I_{S} \leq I_{D}$ and $V_{D S}=0$, at different values of reflected power from port-4 of circulator the condition of MOSFET absorption was satisfied for all values of reflection from port-4 of the circulator as shown in Table 6. 
Elliot O. Omoru et al., International Journal of Emerging Trends in Engineering Research, 8(9), September 2020, 6488 - 6495

Table 5: Source and drain parameters deduced from plots

\begin{tabular}{|c|c|c|c|c|}
\hline $\begin{array}{c}\text { Reflected } \\
\text { RF power }(\mathrm{dBm})\end{array}$ & $\begin{array}{c}\mathrm{V}_{\mathrm{DS}} \\
\text { (Volt, Source) }\end{array}$ & $\begin{array}{c}\mathrm{V}_{\mathrm{DS}} \\
\text { (Volt, Drain) }\end{array}$ & $\begin{array}{c}\mathrm{I}_{\mathrm{S}} \\
(\mathrm{mA})\end{array}$ & $\begin{array}{c}\mathrm{I}_{\mathrm{D}} \\
(\mathrm{mA})\end{array}$ \\
\hline 19 & 0.00 & 1.4 & 0.72 & 0.72 \\
\hline 13 & 0.00 & 0.25 & 0.14 & 0.14 \\
\hline 5 & 0.00 & 0.38 & 0.020 & 0.020 \\
\hline 3 & 0.00 & 0.14 & 0.07 & 0.07 \\
\hline
\end{tabular}

Table 6: Truth table condition for MOSFET absorption

\begin{tabular}{|c|c|c|}
\hline Reflected power, $\mathrm{P}(\mathrm{dBm})$ & $\begin{array}{c}\mathrm{V}_{\mathrm{DS}} \text { at source } \\
\text { terminal }=0\end{array}$ & $\mathrm{I}_{\mathrm{S}} \leq \mathrm{I}_{\mathrm{D}}$ \\
\hline 19 & True & True \\
\hline 13 & True & True \\
\hline 5 & True & True \\
\hline 3 & True & True \\
\hline
\end{tabular}

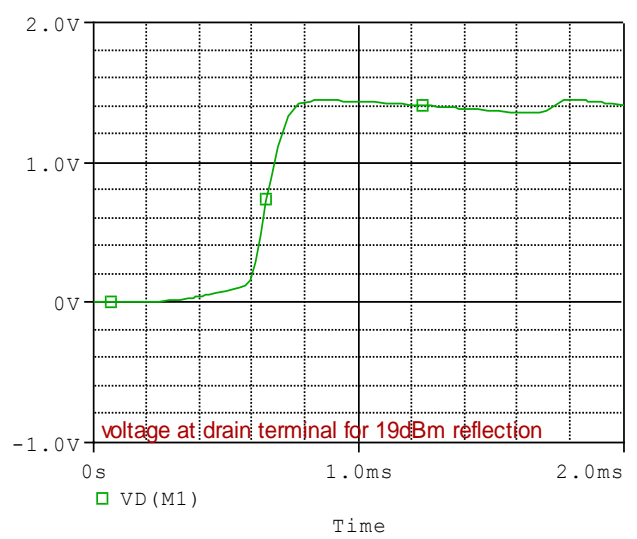

(a)

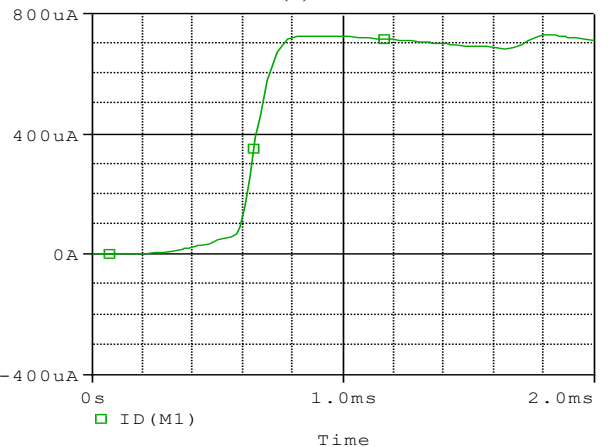

(b)

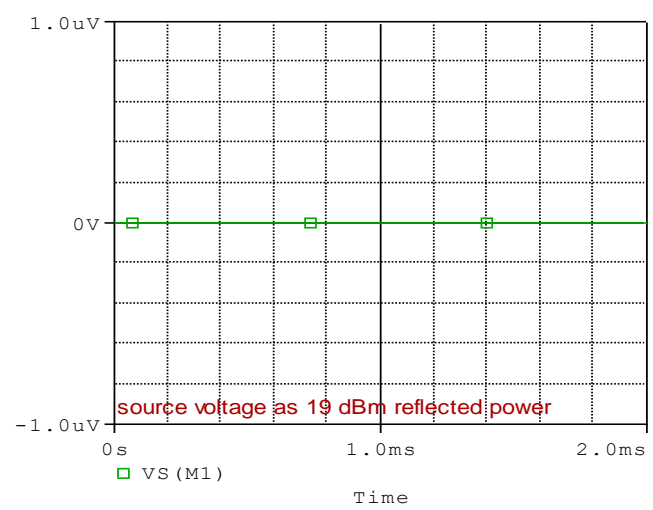

(c)

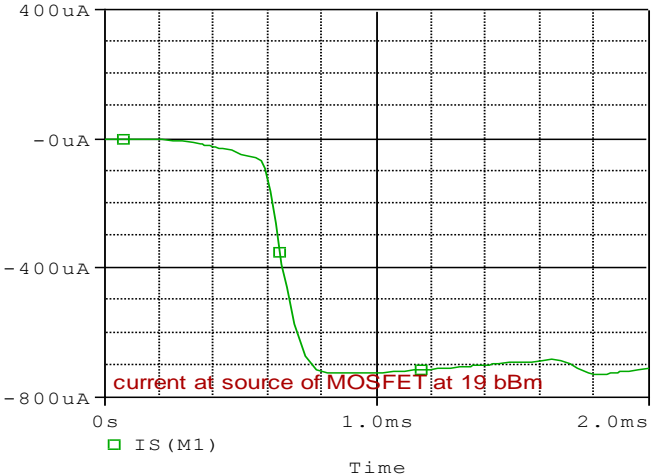

(d)

Figure 8: Plot for MOSFET drain (a) voltage, (b) current, and source (c) voltage, and (d) current.

\section{CONCLUSSION AND FUTURE WORKS}

The proposed model has theoretically and practically confirmed that the destructive interference caused by reflection from $R_{x}$ branch of a $5 \mathrm{G}$ base station can be avoided by using MOSFET technology to absorb reflected radio frequency signal. In addition to this, to verify the consistency of the model all values of reflection from port-4 of the circulator met with the condition for MOSFET absorption. Furthermore, a MOSFET was used in this model because it has the advantages of working as a passive element like resistor, capacitor, and inductor.

This research can be further extended by designing a DC to DC boost converter for the source terminal of the MOSFET for the purpose of modifying the primary DC currentto alevel required to power high speed data converters like Digital to Analog Converters (DACs), Analog to Digital Converters (ADCs), and other communication devices used in $5 \mathrm{G}$ base stations.

\section{REFERENCES}

[1] Sanae E. Hassani, Abdelfatteh Haidine, and Hayat Jebbar, "Road to 5G: key enabling technologies," J. of Communications, vol. 14, no. 11, pp. 1034-1048, Nov. 2019.

[2] Stefan Parkvall, Erik Dahlman, Anders Furuskar, and Mattias Frenne, "NR: The new 5G radio access technology," IEEE Communications Standards Magazine, vol. 1, no. 4, pp. 24-30, Dec. 2017.

[3] Godfrey A. Akpakwu, Bruno J. Silva, Gerhard P. Hancke, and Adnan M. A. Mahfouz, "A survey on 5G networks for the internet of things: Communication technologies and challenges," IEEE Access, vol. 6, pp. 3619-3647, 2017.

[4] Christian Hoymann, David Astely, Magnus Stattin, Gustav Wikstrom, Jung Fu Cheng, Andreas Hoglund, Mattias Frenne, Ricardo Blasco, Joerg Huschke, and Fredrik Gunnarsson, "LTE release 14 outlook," IEEE Communications Magazine, vol. 54, no. 6, pp. 44-49, June 2016.

[5] Akhil Gupta and Rakesh K. Jha, "A survey of 5G network: Architecture and emerging technologies," IEEE Access, vol. 3, pp. 1206-1232, 2015.

[6] Joseph Isabona and Viranjay M. Srivastava, "Downlink massive MIMO systems: achievable sum rates and energy efficiency perspective for future 5G systems," Wireless Personal Communication, vol. 96, no. 2, pp. 2779-2796, Sept. 2017.

[7] Raja Muthalagu, "A literature survey on transceiver designs in multiple-input multiple-output and orthogonal frequency division 
Elliot O. Omoru et al., International Journal of Emerging Trends in Engineering Research, 8(9), September 2020, $6488-6495$

multiplexing systems," J. of Communications, vol. 13, no. 2, pp. 45-59, Feb. 2018

[8] Duong T. T. Tu, Nguyen T. B. Phuong, Pham D. Son, and Vu V. Yem, "Improving characteristics of $28 / 38 \mathrm{GHz}$ MIMO antenna for $5 \mathrm{G}$ applications by using double-side EBG structure," J. of Communications, vol. 14, no. 1, pp. 1-8, Jan. 2019.

[9] Pavel Livshits, Moshe Gurfinkel, and Yefim Fefer "VLSI MOSFETs lifetime reduction caused by impedance mismatch," Microelectronics Engineering, vol. 88, no. 1, pp. 28-31, Jan. 2011.

[10] Zohaib Hameed and Kambiz Moez, "Design of impedance matching circuits for RF energy harvesting systems," Microelectronics Journal, vol. 62, pp. 49-56, April 2017.

[11] Elliot O. Omoru and Viranjay M. Srivastava, "MOSFET based absorber of reflected signal in 5G massive MIMO base station A circuit perspective," Journal of Communications, vol. 15, no. 11, Nov. 2020, in press.

[12] William D'Orazio and $\mathrm{Ke} \mathrm{Wu}$, "Substrate-integrated-waveguide circulators suitable for millimeter-wave integration," IEEE Transactions on Microwave Theory and Techniques, vol. 54, no. 10, pp. 3675 - 3680, Oct. 2006.

[13] Kota Mitsuya, Yuya Shoji, and Tetsuya Mizumoto, "Demonstration of a Silicon waveguide optical circulator," IEEE Photonics Technology Letters, vol. 25, no. 8, pp. 721-723, April 2013.

[14] Leonid Belov, Victor Kochemasov, and Sergey Smolskiy, Handbook of RF, microwave, and millimeter-wave components, Artech Publication, 2012.

[15] Derek H. Martin and Richard J. Wylde, "Wideband circulators for use at frequencies above $100 \mathrm{GHz}$ to beyond $350 \mathrm{GHz}$," IEEE Transactions on Microwave Theory and Techniques, vol. 57, no. 1, pp. 99-108, Jan. 2009.

[16] Ahmed Moussa, Yaser Khalaf, and Ahmed Khalil, "Design of a novel circulator for wireless transceivers," Int. Conf. on Microelectronics, Cairo, Egypt, 29-31 Dec. 2007, pp. 1-4.

[17] Chia H. Chang, Yu T. Lo, and Jean F. Kiang, "A $30 \mathrm{GHz}$ active quasi-circulator with current-reuse technique in $0.18 \mu \mathrm{m}$ CMOS technology," IEEE Microwave and Wireless Components Letters, vol. 20, no. 12, pp. 693-695, Dec. 2010.

[18] Sen Wang, Chih H. Lee, and Yan B. Wu, "Fully integrated 10$\mathrm{GHz}$ active circulator and quasi-circulator using bridged-T networks in standard CMOS, " IEEE Trans. on Very Large Scale Integration (VLSI) Systems, vol. 24, no. 10, pp. 3184-3192, Oct. 2016.

[19] Shih C. Shin, Jhih Y. Huang, Kun Y. Lin, and Huei Wa, "A 1.5$9.6 \mathrm{GHz}$ monolithic active quasi-circulator in $0.18 \mu \mathrm{m} \mathrm{CMOS}$ technology," IEEE Microwave and Wireless Components Letters, vol. 18, no. 12, pp. 797-799, Dec. 2008.

[20] Edward A. Ohm, "A broad-band microwave circulator," IRE Transactions on Microwave Theory and Techniques, vol. 4, no. 4, pp. 210-217, Oct. 1956.

[21] Douglas K. Linkhart, Microwave Circulator Design, $2^{\text {nd }}$ Ed., Artech House, Bostan, 2014.

[22] N. Sugimoto, T. Shintaku, A. Tate, H. Terui, M. Shimokozono, E. Kubota, M. Ishii, and Y. Inoue, "Waveguide polarization- independent optical circulator," IEEE Photonics Technology Letters, vol. 11, no. 3, pp. 355-357, March 1999.

[23] Petri S. Heljo, Miao Li, Kaisa E. Lilja, Himadri S. Majumdar, and Donald Lupo,"Printed half-wave and full-wave rectifier circuits based on organic diodes," IEEE Transactions on Electron Devices, vol. 60, no. 2, pp. 870-874, Feb. 2013.

[24] Shohei Imai, Shoichi Tamaru, Kazuhiro Fujimori, Minoru Sanagi, and Shigeji Nogi, "Efficiency and harmonics generation in microwave to DC conversion circuits of half-wave and fullwave rectifier types," IEEE MTT-S International Microwave Workshop Series on Innovative Wireless Power Transmission: Technologies, Systems, and Applications, Kyoto Japan, 12-13 May 2011, pp. 15-18.

[25] Michael Roberg, Tibault Reveyr and, Ignacio Ramos, Erez Avigdor Falkenstein, and Zoya Popovic, "High-efficiency harmonically terminated diode and transistor rectifiers," IEEE Transactions on Microwave Theory and Techniques, vol. 60, no. 12, pp. 4043-4052, Dec. 2012.

[26] Seyyed A. Ayati, Debashis Mandal, Bertan Bakkaloglu, and Sayfe Kiaei, "Adaptive integrated CMOS circulator," IEEE Radio Frequency Integrated Circuits Symposium (RFIC), San Francisco, CA, USA, 22-24 May 2016, pp. 146-149.

[27] Douglas K. Linkhart, Microwave circulator design, $2^{\text {nd }}$ Ed., Artech House, 2014.

[28] Mike Golio, RF and microwave semiconductor device handbook, CRC Press, USA, 2003.

[29] A. S. Sedra and K. C. Smith, Microelectronic circuits: theory and applications, $7^{\text {th }}$ Ed., Oxford University Press, 2014.

[30] R. L. Boylestad and L. Nashelsky, Electronic devices and circuit theory, $11^{\text {th }}$ Ed. Pearson Prentice Hall, 2012.

[31] Ravinder Kumar, Munish Kumar, and Viranjay M. Srivastava, "Design and noise optimization of RF low noise amplifier for IEEE standard 802.11a WLAN," Int. J. of VLSI Design and Communication Systems, vol. 3, no. 2, pp. 165-173, April 2012.

[32] Steve Winder, Analog and Digital Filter Design, $2^{\text {nd }}$ Ed., Newnes, Elsevier, Oct. 2002.

[33] Viranjay M. Srivastava, K. S. Yadav, and G. Singh, "Double-pole four-throw RF CMOS switch design with double-gate transistors," 2010 Annual IEEE India Council Int. Conference (INDICON-2010), India, 17-19 Dec. 2010, pp. 1-4.

[34] Xiao P. Chen and $\mathrm{Ke} \mathrm{Wu}$, "Substrate Integrated Waveguide Filter," IEEE Microwave Magazine, vol. 15, no. 5, pp. 108-116, July - Aug. 2014.

[35] Viranjay M. Srivastava and G. Singh, MOSFET technologies for double-pole four throw radio frequency switch, Springer International Publishing, Switzerland, Oct. 2013.

[36] Negar Reiskarimian, Jin Zhou, and Harish Krishnaswamy, "A CMOS passive LPTV nonmagnetic circulator and its application in a full-duplex receiver," IEEE Journal of Solid-State Circuits, vol. 52, no. 5, pp. 1358 - 1372, May 2017.

[37] Viranjay M. Srivastava, K. S. Yadav, and G. Singh, "Explicit model of cylindrical surrounding double-gate MOSFETs," WSEAS Trans. on Circuits and Systems, vol. 12, no. 3, pp. 81-90, March 2013.

[38] Vadim Issakov, Microwave circuits for $24 \mathrm{GHz}$ automotive radar in Silicon-based technologies, Springer, 2010. 